\title{
The Dimensions of Arab Regional Security and Its Perceptions for the Period (2010-2017)
}

\author{
Hasan Abdullah Al-Dajah* \\ Associate Professor, Dept. of Media and Strategic Studies \\ Al-Hussein Bin Talal Univ. \\ Qais Salem Al-I'weisat \\ PhD. Political Science, Researcher in Political Affairs
}

\begin{abstract}
This study aimed at pin-pointing the Arab Regional Security and its perceptions, and analyzing that through the effect of the modern strategic transformation in the Arab reality, represented in revolutions of the Arab Spring, and for the sake of achieving this objective, the study started from a principal objective meaning, recognizing the dimensions of the Arab Regional Security and its perceptions. The study employed the analytical descriptive method, and the study had deduced a group of results, the most important of them: is that the comprehensive security is connected with the collective security of states, that is because any defect in one affects negatively the security of other states. And that the Arab regional security depends on coordination among the security policies of the Arab States, and cooperation in carrying them out, and all that demands reformulation of the theory of regional security of the states due to the civilized identity, and the highest values of the Arab States altogether, to confront the internal and external dangers. Also the concern is concentrated on the political security at a great degree rather than else.
\end{abstract}

Keywords: Security, The Arab National Security, The Regional Security, The Arab Regional Security, The International and Regional Forces.

DOI: $10.7176 /$ RHSS/9-22-01

Publication date: November $30^{\text {th }} 2019$

\section{Introduction:}

The comprehensive Arab Regional Security faces many challenges and threats, of them internal and external, reality is that these dangers make the Arab Region on the standard, especially in light of the hasting incidents that they witness; perhaps these challenges are not confined to a state at its limit, but covers the common Arab States, of them the political, security, economic, social and the cultural challenges and else.

Perhaps the Arab Region, that is considered of the most important regions at the world level, never to calm a day, because of the regional and international powers that did not stop creating crises in it, as service to its objectives and interests, without considering the Arab interest. The Arab Spring had represented an ideal means of these powers for the sake of settling its intervention and penetration at a dangerous form more than it was, and as an effect of that the Arab Regional Security because a case of weakness infront of those schemes, in time the units of this system suffer from permanent internal problem in all domains.

It is noticed that indicators show the extent of competition excessiveness among the regional powers and conflict among the international powers on the Arab Region, especially in the States in which revolutions and popular protests took place, and that the Arab Regional security is the greatest loser, with what the occurrences devolved upon, and the matter became more dangerous the thing that obliges radical analyses that guarantee change at a positive form.

\section{Significance of Study:}

The significance of study starts from the attempt of pin-pointing the Arab Regional Security dimensions and its perceptions, where this the latter witnesses a strategically transformation on all sides.

The scientific significance springs from its being include indicators to the whole concept of the Arab Regional Security dimensions and its perceptions. This study also forms a tributary to the scientific literatures in political science.

But what relates with the scientific significance, this study may form an attempt of complete diagnosis of problems, in front of decision-makers in the Arab States, to benefit from them achieving the Arab Regional Security.

\section{Problem of Study:}

The problem of study conceals in studying dimensions of the Arab Regional security and its perceptions since the endings of the year 2010 till the end of 2017 after the regional incidents happening in the region, and directly on the Arab Regional security, the matter that shared in raising many inquiries about the destiny of the Arab 
Regional security, that called for preparing this study.

\section{Inquiries of Study:}

Due to problematic study and its main inquiry it is: What are the dimensions of the Arab Regional Security and its perceptions? There are a number of subsidiary inquiries, this study will attempt to answer them; they are:

- What is the concept of the Arab Regional Security and its synonyms?

- What are the dimensions of the Arab Regional Security?

- What are the perceptions of the Arab Regional Security?

\section{Objectives of Study:}

- Clearance of the Arab Regional Security.

- Disclosing the dimensions of the Arab Regional Security.

- $\quad$ Laying perceptions of the Arab Regional Security.

\section{Limits of Study:}

The period from the endings of the year 2010 until the year 2017, for what to this period a significance in the Arab Region, where the strategic transformation represented in the Arab Revolutions and popular protests, that are reflected directly on the dimensions of the Arab Regional Security, this study has its time and place limits, they are:

Firstly: time limits: the limits of study from their time range stretch since the endings of the year 2010 to the end of the year 2017, until both researchers can obtain the satisfactory amount of information.

Secondly: the place limits: the limits of study from the place range stretch in the Arab Region that covers all the Arab States.

\section{Methodology of Study:}

Due to multitude of the Arab Regional Security concept dimensions, it had been depended in this study on the analytical descriptive method, and as it is well known, this method is performed on the basis of analyzing the parts from which the phenomenon consists to obtain the information concerning this phenomenon. And the more stages of analysis multitude, the most available of comprehensive perception was for the phenomenon. The analytical method is performed on three partitions, they are: explanation, criticism and invention.

Both researchers initiated to employ the descriptive analytical method, on the basis that this study needs clearing the concept of the Arab Regional Security and its dimensions. This method depends raising these incidents as they are in reality, and concerns about describing them an accurate description, together with analyzing them. This is what is applied on actions of study in respect of the Arab Regional Security reality in light of the international and regional powers conflict, their danger and how to treat them.

\section{The Related theory:}

The theory employed in this study is the "theory of analyzing systems": and in accordance with (Morton Kaplan's) raising, the theory of analyzing systems concerns with the wholly interactions, without being within the frame of the parted study of the different patterns of the partial interactions, and then assists on analyzing the behavior of states in a special frame directs the concern to interaction in between at a wholly frame, and assists to reach the repeated models of how work of the international systems, and specifies prospects of their organization, factors of balance, and defect that governs the development of the main and subsidiary international systems, and their transference from one form to another. Therefore, the Arab Regional Security, represents one of the international systems, that appropriate with this theory and represents a basis in understanding the causes and the how of mutual interaction among the forming units of it, the thing that shares in pin-pointing prospects of organization in its behavior (Mustafa, 2013).

Both researchers initiated to employ this theory considering that the matter of the Arab Regional Security is the product of each unit security of the Arab Regional system units, and outputs of the national security were considered from the basic inputs of the Arab National security, and this security can never be achieved without each state to work on achieving its comprehensive internal security for all dimensions (political, economic, social, security and else..) and then a part of the whole will be with other units, and this theory agrees with the significance of this study and its content.

\section{Concepts and terms of study:}

Security: Bari Buzan defines it as liberation from threatening, and ability of states and communities to keep their independent identity and safety of occupation against powers of change, that they consider them antagonist and aggressive, and covers the National Security: the military security, that is, the attacking and defensive abilities of states and perceptions of states about intentions each of them, and the political security, that guarantees the 
organizational stability of states, organizations of the government, the ideologies that grant it legitimacy, the economic security represented in resources, financing and the necessary markets to conservation of acceptable levels of welfare and authority of the state, but the societal security is the ability of communities to conserve their traditional patterns for language, culture, identity, customs and the national identity within acceptable conditions for development, and the environmental security by conservation on the world and local setting of the states considering it the basic support system, upon which all other human projects depend, and these five sectors do not work in isolation from each other, and each of them specifies an axial spot in the frame of problematic security, and organizing priorities and all of them are altogether weaved in strong net of links (Buzan, 1991).

And in accordance with Peter Ghali's raising security is not confined to liberation from the external military threatening, and does not only touch the safety of the state, its sovereignty and its regional unity, but stretches to cover the political, economic, and social stability, because security is related with internal stability at the amount of what is connected with the external aggression, and in this definition is an indication to the importance of other dimensions, where cessation does not be done at the military dimension, but also covers the political, economic and social dimension (Ahmad, 2016).

\section{The Arab National Security:}

It is meant by it insuring the regional strength, the political stability and the economic integration among parts of the Arab World, and enhancing the machineries and rules of the mutual Arab labor including the defensive abilities (Sa'del Deen, 2000).

\section{The Regional Security:}

It is meant by security in its regional frame: integration of a group of states, that are gathered in between them by a group of interests and mutual objectives, and establish in between them economic and military coalitions as a means of guarantying or building the regional security, and it is also defined that it is: a political concept called on the mutual security policy crystallized by the political units forming the regional system to confront the risks of the mutual external threats of the Region (Wahibah, 2014).

The Arab Regional Security: can be defined as provided and worded upon in the Arab League Charter as: "Ability of the Arab Nation on defending its security, rights, forming its independence and sovereignty on its lands, developing abilities and Arab Possibility at all different political, economic, cultural and social domains, leaning on the military and diplomatic ability, taking into consideration the National Security needs for each state, available possibilities, internal, regional, and international variables, that effect the Arab Regional Security" (Hasan, 2000).

\section{The Regional and International Powers:}

They are the states that practice an effect on the level of the region a whole. The German Institution for Worldly and Regional specifications of regional powers, at a high accurate degree, for it was considered possessing the following characteristics: regional power traits, excellent military energies, economic, demographic, political, and dogmatic performs with decisive role in laying the security agenda of the region, and in demarcating its geographic borders, in making its dominating dogma, and merging in a truthful mergence in the region, possessing good relations in the region and out of it, and other powers in the region and out of it confess with its regional position, and as its well known that the non-Arab regional powers are usually given a name to Turkey, Iran and Israel (Al-Sulh, 2013).

But the international powers mostly mean both great powers, who compete on the Arab Region, they are: The United States of America, and the Federal Russia.

Both researchers define the concept of Arab Regional Security that it is "The ability of Arab States to conservatism of their values, culture their possibilities: human and materialistic, unity of their lands and defending them and protecting them from internal and external threats. They cover the political, social, economic and military powers, through which it resembles a defender against he who his soul converse him to attempt change their values or aggress against its possibilities". Thereupon at analyzing this concept into elements, both researchers find that it covered the following constituents:

- Materialistic ability: that is the state to be able from all sides satisfied with itself and resources.

- Values: are the matters related with sovereignty, independence, advancement and progress.

Culture: it is the inherited materialistic and morale.

- Human efficacies: efficiency of its individuals in all domains.

- Lands unity: protection of its internal and external borders.

- $\quad$ Defense and protection: its military ability to protect its independence and keep its sovereignty.

- Internal threats: all internal challenges like unemployment, poverty, illiteracy and difference in values.

- External threats: all external dangers.

- Political power: political presence, coalitions and memberships of regional and international 
organizations.

- Economic power: the national efficacies that rise with the agricultural, commercial and technical demands of the state.

- Social power: cohesiveness, and the popular harmony about the highest values.

- Military power: it is the number and equipments of the Armed Forces, that represent protection of the state from the internal and external threats.

- Deterrence Power: total of military power and coalitions that prevent any external greed's.

\section{Previous Studies:}

Bobash study, The Arab National Security in Shadow of Present Worldly Transformations, (2010). The study came on three primary axes: the first tackled the Arab concept of the National Security, but the second axis: dealt with the reality of the Arab National Security and its challenges, while the third axis: discussed confronting the internal and external challenges, that the Arab National Security faces. The study deduced that the Arab Region confronts challenges, and crises became clear in aspects of dispersion and disconnection, and in attempts of penetration, piercing and contrition in the torn Arab body, and never to confront these challenges except through United Arab Strategy depends in the first place on developing and employing the Arab possibilities, with what serves the Arab interests inside peaceful limits, and starts form the security concept of comprehensive satisfaction, that is security never be confined to the military side, but also covers new other dimensions, political, economic, cultural, and else.

Ismael's study, "Future of the Arab Group Security in the Light of Arab Revolutions, (2013).in this study challenges that confront the Arab Group Security had been tackled, either the internal, that connects with the environment Arab Relations, and the political, security, economic, and social conditions, and decision-making in the Arab League, absence of economic integration and challenging terrorism after revolutions, but the external of challenges represented in the Israeli occupation, and the American existence in the region, the Irani occupation of the Emirati Islands, and the Regional conflict among states of the neighborhood (Turkey, Iran, Israel). The study tackles the conditions of activating the system of the Arab group security and enhancing the role of Arab organizations, without regionalism like the African Union, Council of Gulf cooperation, reform of political systems and the Arab League, and the effect of revolutions on the system of group security that caused an evident coup d'tat in the regional powers balances to happen.

They study deduces that confronting challenges and risks oblige the significance of starting Arab reconciliation process, and removing obstacles that prevent it, pushing the process of comprehensive reformation, asserting the significance of popular diplomacy in solving Arab disputes, activating the role of the Arab League through several points covered amending the charter, laying prerequisite machineries to carry out decisions, and the follow up of the league decisions and else.

Shalabi's Study: Arab National Security and the Competitive Regional Strategies threats on Sovereignty in the Middle East Region, (2015). In the second chapter of this study role of international variables in the environment of the Arab National Security had been tackled, and the Russian role in the Arab Region. Enlarging the NATO coalition strategy, challenges of the Arab National Security Environment, either they are political, security or economic, and the effective factors on the environment of the Local Arab National Security, regional and international.

The study deduces that the Arab Region lives under the influence of many regional projects each of them seeks to empower its sovereignty and imposes its domination, in light of anarchy and case of weakness that the Arab Regional system suffers from, continued suffering from occupation, interventions and foreign pressures, and lately the Arab Revolutions formed an appropriate environment to crystallized international and regional projects started to compete on sovereignty in the Arab Region, through showing projects of each of Turkey, Iran, Israel, United States of America, and Russia, and competition of the regional strategies on sovereignty in the Middle East Region that deduced, in the end, true threats against the Arab National Security.

A study by - Holmquist \& Rydqvist (2016). The Future of Regional Security in the Middle East-Four Scenarios, tackles the future points of view concerning the regional security in the Middle East, especially the Arab States and covers the axes: energy, security, challenges of geography, political competition after the Arab Revolutions, responses of the regimes by the military tool, non-government al armed effective parties, and policy of the United States in the Middle East.

The study deduces four scenarios for the Arab Regional Security: the first; the United States gives up of the policy of caution, keeps on an active policy in the Middle East, and Saudi Arabia remain viewing that Iran threatens stability in the region, the second; escalation of conflicts among great powers in the region and clash of Iran and Saudi in Syria, the thing that leads to waging direct war between the two countries, the third is relaxation, and leadership of the United States: the Middle East witnesses relations more stable, and Saudi and Iran mutual interests, the fourth: peace in the region, where Iran and Saudi perceive that they cannot endure cost of war, and they both must endure the responsibility of security and concentrate on trade and build trust in the 
Gulf.

\section{Firstly: Concept of the Arab Regional Security:}

Security is considered a basic element in life at its different degrees and its development since the beginning of mankind creation, it is the most powerful prop for its growth, development and progress, and it is contradiction of fear, and since the end of the second World War, this subject obtained more of leaders' concern of politicians and militants, and tackled by research and investigation by strategic theorists and researchers, and no national strategy is vacant from complete imagination of security and protection of values and vital interests of a community or a certain state, and attempt of imposing the will from any source either at the internal level, the regional or international (Ka'wash, 1989,7).

And the Arab security is the security of the Arab States altogether, in the context of their interaction all and their junction as a regional organization at the same time, by this meaning to the Arab security is a regional security parallel to being a national securityand the regional security does not point to a geographic extension of the national security of the state or nation, but to a different philosophy (Al-Marhoon,2016).

\section{Concept of Regional Security and Synonyms:}

Writers and contemporary thinkers differed about the concept of security, its dimensions, constituents and styles of achieving it. And the employed named things had been multitude in this domain, such as the national security or the National Security, Public security, collecting security, mutual security and the Regional security, and with aggravation of crises and contemporary problems affecting the safety of man and his properties, the most specific security statements, such as the industrial security, nutritious security, and the environmental security....and else (Bobash, 2010).

The regional security is more modern term, emerged evidently between both World Wars, to express the policy of a group of states belong to one region, seek through laying and organizing a military cooperation to states of that region to prevent any foreign or external power from intervening in that region, and it is a type of coalition among states of a certain region to organize defense of that region, and the essence of this policy. It is the regional mobilization from one side, confronting the foreign powers on that region from another side, and protecting the prevailing condition from a third side (Rabe , 1984).

The regional security relates with a region in which there is cooperation among its units, exchange of trust and homogeneity, so achieving regional security demands premature availability of cooperative relations among units of the regional systems, and it is what you work through performing a construction aiming at planting trust among members of the system, therefore the regional security does not form just pure gathering the national security for each of states locating within that region, it is enlisted under the concept of satisfaction of all parties inside the regional frame, that have exchanged interests, and continuous to find joint solutions to joint issues, where to guarantee rights and interests of all parties in an equivalent and balanced form (Lubna, 2010).

And in the period after the war, the concept of security with multitude phases. Buzan(1983) in his books entitled "People, States and Fear" indicates that the concept of security "was very narrow", so its aim was to make available "a larger frame of security", includes concepts had never been discussed before like the regional security, or the social and environmental sectors, and here appears (Buzan's) plain way more comprehensive to define security (Stone, 2009).

Robert Jervis(1984) defies the security systems that they are "cooperation of a group of states to manage their conflicts, and avoid war across extinguishing the labyrinth of security through its works and its suppositions related with works of others of states alike", the security systems cover abroad sector from the behavioral rules, such as un-employing power, and respecting the acting international borders and else,. Various regional structures as they are security systems, like: organization of security and cooperation in Europe. And considering some regional procedures to limit armament like specifying the empty territories from nuclear arms or conventions of the Armed Forces in Europe for the year 1990. The success extent of these regional systems depend on the extent of respecting its standards through the degree of what its institutions impose of motives and penalties(Sheibi, 2009).

\section{The Arab Regional Security as a Synonym of the Regional Security:}

The Arab Security turns away from that case of stability, that covers all the Arab region away from any type of threats either from inside or from outside. By this specification this trend concentrates on the idea of joint security for Arab countries, in order the national security becomes a synonym of the regional security, and it is more common among the concerned people with issues of the national security. Hweidi (1986)views that national security is what the state performs or a group of states, that one collective system combined of procedures in limits of their ability, for conserving their entity and interests at present and future, together with observing the local and international variables, so the collective security is a definite necessity to achieve the Arab security, for what it has of feast benefits on condition that to commit to rules and regulations of the collective work (Jizan, 2011).

And the Arab National Security is like a regional security resulting in local interactions among parties of the Arab Region, and in similarity in content that the concept of the national security is employed to clarify the 
security of the nation and not only the security of the native land, and from this point is its relative mystery.

Whenever the native land is the nation, that is when we are in front of a national state, the concept of the national security becomes completely equivalent to the national security concept, and it is excused in this case employing any of them both to guide to the other, but when the nation is distributed among peoples of different and independent states, like the case of the Arab Nation at present, the concept of the national security becomes a theoretical or suppositive concept to a great degree, and in this case its effectiveness is measured with the intent of the ruling Arab systems commitment to the objectives to which the Arab peoples aspire, and measured also with the extent of effectiveness of the system of collective security, worded on in the Agreement of Joint Arab Defense signed in 1950 (Nafia', 2016).

It seems that there is an evident significance on employing the synonym between the concepts of nationalism for the term of Arab security, and in this study employing the articulation of the Arab regional security at a large form in considering the regional security as the term with most comprehensive in time of coalitions with their different forms either with the political nature or the economic one and else.

\section{The National Security as a part of the regional Security:}

Wolter Lippman (2013) had defined the National Security as "The state is peaceful when it is not forced to sacrifice its legitimate interests in order to avoid war, and be able to protect those interests, and the security of the state should be equal to the military power and the military security, in addition to the possibility of resisting the armed attack and overcome it" and we can take Wolfers(1952)definition: when he defined it "the national security means protection of values, that previously acquired, it increases and decreases according to ability of the state to deter the attack or overcome it", also (Henry Kissinger) defines it as "security by behavior, that the community by which seeks to keep its right in survival" (Manser, 2009).

James Rosenau., the theorist and American Politician views that security is an instrumental objective at a limited domain, and consists of four independent and subordinate variables, and can be specified with personal factors as the social qualification, values concepts, roles, organizational factor as associations, formal organizational structures, and non-formal, bureaucratic policies and its internal environment, and include the political culture, human resources and non-human resources, its external environment covers conditions of power and relations and communications. Ali Hilal Ali views that the national security is not pure a military issue, but it is a matter with multitude of factors and dimensions in which politics, economics and geography intermix with militarism and social condition with the power of the state, the political system with strategy, so security has its comprehensive concept, and threat is internally and externally integrated, Nakirah, 2011).

Security in accordance with Nafia's(2015) point of view covers two sides: the first, size of what each party possesses from elements of power with its comprehensive meaning, the smooth and the solid, and the second, efficiency of employing these elements at dealing with crises, challenges, and sources of threatening, and it is natural for every doer to aspire to achieve the security of the native land depending on his powers personal resources alone, and this is not available except for a limited number of international doers, and then the overwhelming majority of them refuges to, especially those confronting permanent and dangerous security threats, into concluding bilateral treaties or collective with other doers to achieve this purpose .

Due to non-existence of one definition agreed upon, so there are three trends in this domain: the real trend, is that the strategic valuable school is represented, and that views the security as a pure value and connects it with issues of independence, and the national sovereignty, so this trend connects the national security with the strategic military security, that was expressed by the school of power in the international relations, and the strategic economic trend: connected the national security with the economic dimension that includes insuring the vital economic resources, and the economic occupation of war, then development and the integrative trend, that is represented by the comprehensive societal school, and concentrates on the comprehensive dimensions of security and covers, the political dimension, the economic, the military, the environmental, the social dimension, and else (Abdel Wahid, 2014).

From what preceded of definitions it is clear that the national security forms a part of an integrative security system of the political units in a certain region, and if security was not parted, but the regional security cannot be except from the total of the national security of states, and this is applied on the matter of the Arab Regional Security.

\section{Secondly: dimensions and determinants of the Arab Regional Security:}

\section{Determinants of the Arab Regional Security:}

From the most important labyrinths that prevent achieving the Arab Regional Security is the issue of concentration on one of the national security sides neglects or forgets other dimensions, so after the independence of the Arab States, concern was wreaked upon the political dimension of the Arab Regional Security rather than paying attention to other dimensions, and in a subsequent period concentration had been done on the military dimensions because of the Israeli occupation, then 1967 defeat, and concentration in a second period started on the economic dimension, and in the practical experience the concentration was wreaked in the beginning upon hastening operations of affectation accompanied by negligence of agricultural sectors, and 
the animal wealth, so at once emerged who calls for concern about nutrition security, especially after the qualitative transformation in the housing development in the majority of Arab states since the beginning of seventies, for some of Arab states to refer to newly turning around to the agricultural sectors to limit as far as possible from its ability from threatening its nutritive security, thereupon the regional security is dimensions integrative, that means absence or negligence one of its dimensions explodes the possibility of achieving other dimensions.

The regional analysis of the security phenomenon, either in its dimensions and determinants, or its threatening, its significance conceals (Ahmad, 2016), in:

1. What characterizes the regional entrance in treating the regional security issues is accuracy and diagnosis, for it concentrates on a certain area, and transfers methodologically and serially from comprehensiveness into specialty, and so encirclement with all security variables, without negligence the international dimension, by action of great powers intervention in interactions of most regions of the world.

2. The regional approach of security observes difference of conditions among territories of the world, that is the regional security principle is that personifies attributes or existence of the regional system, at least, at the political level, for achieving the whole integration and reaching mergence that is hoped by the new occupational theory, for example: it is by passing through the security cooperation considered as an important sector and sensitive, at the same time, for all the political units, so achieving integration of this level allows the integrative operation to spread at highest level.

The operation of performing and managing the regional system differs by its contents and weights from a regional territory to another, and from a security arrangement form to another and in accordance with conditions of performing this system and effectiveness, conditions of the acting military powers balances in the region, pattern of the prevailing interactions among its parties and influence of the international and regional powers in the regional security system, but literatures of international relations had provided a group of props, upon which the regional security system is performed (Al-Harbi, 2008).

Without which the regional security cannot be achieved (Haj, 2016), the most important of them:

1. Put an end to conflicts and struggles and solving them at correct methods to guarantee the internal stability for states of the region and confront the external intervention, that threatens the entity and sovereignty of the region.

2. Giving up part of the national sovereignty, for the sake of enjoying some characteristics, the group security like mutual defense.

3. Working on raising manner of cooperation and integration.

4. Respect of human rights, and activating the role of the civil community, including participation, or showing opinion in managing associations of the regional security system.

5. Considering the regional security an unpartial part of the international security.

And in general there is a group of factors that affect in specifying threats that confront security at the regional level; they are the nature of threat, means its type and dimensions, either the political, economic, military or geographic and place of threat and its trends, that is extent of approach, geographical dimension, or demographic, either it was direct or indirect and extent of its spread and its comprehensive effect for numerous states or specified in one state, time of threat, that is, its present effect, future and the extent of its continuation...is it stead or variable, and also the degree of threatening meaning its strength and danger, for whenever the degree of threatening and danger increased, that demanded a comprehensive mobilization of the regional power to limit its effect and finally mobilizing the resources, it connects with the size and danger of threat and extent of its intensification, the matter in light of which taking appropriate mobilization procedures are done from part of gathering the resources and efforts to limit its effect and dimensions (Al-Harbi, 2008).

\section{The Arab Regional Security Dimensions:}

The Arab Regional Security can be viewed as considered a regional security of a group of geographically adjacent states, in addition to being homogenous nationally and religiously. One of the Arab Regional Security characterizations is that that can be transferred as direct into the consistency of the geopolitical environment, and this latter can be defined as a group of the whole interactions among a group of units or the subsidiary regions located within a certain geographic range, the study of geopolitical environment demands a tripartite layer analysis, the first consists of internal data of the regional states and those located on its frontiers, and the second layer of the prevailing interactions nature within the different regional (subsidiary) units, but the third layer, connects with land and sea borders, especially the prevailing conditions in the strategic straits and tracks (Marhoon, 2010).

The regional security is considered one mass of a group of political units, but it consists of a group of dimensions, of them social, military, economic, or cultural and else.

Firstly: the military dimension:

(Bary Buzan) views that the majority of states specify their security relations from regional starting points and 
not worldly, even if dealt with worldly issues, they incline to the vision of those issues from a regional perspective. So the region dominates the security perspective (Al-Harbi, 2008).

There are a number of indictors that can be leaned upon as a scale to limit the power of the national security from the military point of view. From those indicators: size and formation of forces, and organizing forces and arming them, elasticity, fighting experience, mobilization, war-like production, and the military allies (Khalil, 2000,27).

There are three types of military issues that affect in the path of attaining a regional security: prevention, such as spreading peace- keeping forces for the sake of early caution and carrying out the role of "warmingwire" and constructing on-line canals among leaders of the region and the before-hand reminding procedures in the affair of maneuvers and moving the forces for the sake of (avoiding the accidental conflicts), deterrence: such as concluding defense and military support agreements, having traditional arms, or possessing developed traditional systems, and controlling armament/ disarmament, the thing that covers arms of whole destruction and traditional arms and else of military technology fields or processes of communicated industrial technology transference (Sayegh, 1991,6).

Secondly: the political dimension:

It concentrates on the internal and external policy, the political associations, so the internal policy is that related with the political system, and the form of governments, and in this respect satisfaction at crowds leads to achieve a degree of adherence and internal cooperation, the thing that enhances the national security, but the dimension concerning the foreign policy, concentrates on the diplomatic effort of the state, its possibilities, the technique of the state employment of sources of power, the international organizations, public opinion and policies of other states with vital interests in the region, then effect of that in the ability of states on clarifying its objectives to the international community, there are also the political associations, that in turn concentrate on the trends of the political leadership, experiences and the extent of their ability to affect crowds and the political organizations (Al-Al-Azzazi, 2015).

\section{Thirdly: the economic dimension:}

Means the economic security in accordance with (Crooz \& Nai) absence of threatening with sharp deprivation from economic welfare. And achieving self-satisfaction is a means to achieve that security instead of subduing to economic pressures from outside. The economic sovereignty is observed as "the essence of the national security" and any threat relates with ability of the state to form and design its economic construction is a threat to its national security, and then the surviving of the state and protection of its region integration are not the subject of external threat to the national security or degrading its worldly and regional position, but its economic condition too, it is what had been asserted in the last decade of the twentieth century, together with the growing of the regional and worldly economic coalitions (Abdel Wahid, 2014).

Inspite of the size of the Arab economic abilities either in their natural or human resources and else, that appear great compared with others of regional regimes in the world, but they, till the moment, could not achieve the economic security to their communities and systems, and did not work in creating the lasting development and ability to employ all their resources to achieve their national objectives.

Fourthly: the social dimension:

The social dimension of national security aims at saving security for the citizens at a value increases the growing of feeling with loyalty and belongingness without performing social justice through desire of approaching differences among classes, and developing services, security will be exposed to danger (Zaki, 2016).

And man's security emerges from concentration of protection from threats that his life and his freedom from one side are exposed to, and achieving the lasting development, that fulfills the present generation's needs without harming the ability of the coming generations to fulfill their private needs from the other side. Achieving the comprehensive security of the Arab human needs concern, investment with his human energies, that is represented by youths, at the first degree, and his natural resources in shadow of legislations, and a social system transfers the community from needs perspective into the human rights (Al-Gharaibah, 2013).

Fifthly: the cultural dimensions:

The cultural dimension is performed on protecting thinking, beliefs, conserves customs, traditions and values of the Arab states, and it is that enhances and insures the start of national power sources at all domains in confronting external threats, internal challenges, enlarges the feeling basis with freedom and dignity, insures the native land and the citizen by ability to achieve a degree of welfare appropriate to citizens, and improve their financial conditions at a continuous form, the cultural role is very significant in improving the native land from the cultural dissertations of globalization and conflict of civilizations, if we take it in the comprehensive concept including thinking, culture, education, media, arts and literature (Zaki, 2016).

Sixthly: environment dimension:

According to (Elizabeth L. Chalecki) "It reflects ability of a nation or community to resist rarity of environmental wealth, environmental dangers, or contradictive changes, tensions, or conflicts related with environment", while Bary Buzan defined it that "it is conserving environmental circumstances that support the 
development of human activity" (Ghadeer, 2014).

We deduce from what preceded that the Arab regional dimensions, are like any regional or international coalition, and each is completing the other, and never a comprehensive regional security is to be achieved, except by all its dimensions, either economic, political, social, or security....and else, and regional security of units is achieved through cooperation with states that are connected with a regional unit to protect their interests, and are specified by agreement and charts and coordination is at the level of confronting external and internal dangers, perhaps the European Union, and Council of Gulf Cooperation are the best examples on regional cooperation to protect security, in addition to cooperation and integration in other dimensions.

\section{Thirdly: perceptions of the Arab Regional Security}

The strategic thinkers unanimously agree on that the national security should occupy its position in the strategic political and military thinking, therefore the states made their national security a higher strategic objective, because challenges that confront nations differ by the difference of ages, and times, so they are affected by incidents, variables and differences, thereupon the Arab Regional Security should not be parted, and should be united far away from differences (I'shqi, 2005).

And the security strategic concept can be tackled with what appropriates with this study, through what the American historian (Alfred Chandler's) raising, when defined it by specifying the long run objectives, the specified objectives of the organizer, adopting practical tracks, specializing the necessary resources to attain goals, and transfer the dimension of that meaning from the strategic work gradually from the domain of the military association to the domain of associations, and economic, administrative, political and social organizations (Ghadeer 2015).

The security strategy of the state is specified by decision- makers, in light of visions questionnaire for the vital interests of the state, and availability of the correct perception of the hoped security equation, it is the perception inspired by the political leadership, and obtains its origins from requirements of the internal condition, and the movement of the external regional and international interactions, that is, its perception of work environment and the movement that affects and affected in an exchange form at drawing its security policies and specifying strategies of work to lay those policies into force and in accordance with the theorist Wolfers(1952) they have two sides: subjective, represented in non-threatening directed against acquired and stable, and the other is personal: it is non-fearing the possibility of exposing these values to danger. From here was perception of threat sources considered one of the important stages in the operation of forming security policies and strategies of achieving them, so they have to have existence of perception and aware vision of threat sources and challenges the state confronts - the primary and secondary sources - and non- mixing among them, and that knowledge is the most important of steps by which starts any formation of policies and security strategies (Abdel wahid, 2014).

And the strategy of national security is a philosophic planning joint operation, that is the system of regional security has to be from part of principle comprehensive, it is not finally excluded from any subject wishes to joint it and commit to its standards, the central problematic is represented in collecting between requirements of regional security and specialty of national belonging. This collection does not seem evident, either in the theoretical side or the practical application, and this problematic leads us to an issue implies" does the nationally distinguished neighborhood represent encompassment or vital depth to them, the demand is to re-originate the Arab vision of the geographic neighborhood, being represent a vital depth, not a security, or political encompassment, and in approach of the relationship with the regional power located outside the Arab framework. The Arab policy is concerned with commitment to neutral line stands at one distance from the competitive parties, so in the present regional equation, governed by a sharp pattern of variations, the Arabs will not win from any attempt at the level of external alternatives, but what will happen at that moment more of poling inside the Arab regional system and seek assistance from regional parties and warming the internal public squares in units of the Arab regional system (Marhoon, 2010).

By that it has to stabilize the Arab cooperation at the security level, on an integration basis, makes available the appropriate conditions to perform an integrated regional security system, and consolidated characterized with effectiveness and elasticity and within each state it combines, and leads to performing integrated and equivalent Arab Security relations, and to achieve all that the Arab cooperation, in general, should be done in determination, planning and carrying out the basic programs of constituents that achieve the strategy objectives, and supporting and initiating the joint Arab institutions, developing the necessary canals to achieve this cooperation, in addition to generalizing the bilateral security treaties, or the multitude of parties among adjacent states, seeking to compete authorization of Arab states on Riyadh Arab Treaty for Judicial Cooperation, and exchange of experts among Arab security corps, exchange of visits among responsible of these corps, and concluding meetings among them to discuss mutual security problems, and excuse them to directly communicate to follow up urgent security affairs with mutual concern, without referring to diplomatic methods (Mohyi, 2014).

Approaches of performing the regional security system are multitude as can be possible with distinguishing among four approaches, the first is represented in: what is called the comprehensive security, that supposes 
perception of the system units, the extent of connection among them military, economic and social issues to achieve security and keeping it, and the second approach supposes: the cooperative security, that is, the informal cooperation among the units to develop a group of principles and behavior standards, that are asserted of the extent of commitment through organizing dialogue and discussions, while the third approach, is the coordinated security to coordination of security policies of units to achieve objectives agreed upon, while the fourth approach is supposed to perform arrangement to group security, that is, specifies units in frame of a certain threat, defense resources are directed to deal with (Al-Marhoon,2006).

The subject of the Arab Regional Security is connected with two truths, they both should be a place of continuous contemplation, from the side that the integrated look of the Arab Regional Security concept cannot come once a time, but it has to be a result of consecutive accumulations, from part of group suffering and the individual creative ability to abstraction, and the theory of Arab Regional security is a meeting between practice and perception and perception is not a pure military imagination, but also a political philosophy (Rabe', 1984).

Truly, reformation of the theory of Arab Regional Security, demands reformation of the worn Arab Regional System and its national security theory, that is, depending the causes and pushing elements of that (AlMuneer, 2016), and of them:

- Unity of Arab civilized identity, and values, examples, religion and mutual heritage.

- The strategic location of the Arab Nation in the heart of the world.

- The stolen and exhausted great Arab Wealth.

- Non-stability of coalition with foreign powers that are pushed and moved by interests.

- The Irani danger with its both shares; the nuclear and enlargement in the region.

- The permanent threatening represented by (Israel), that will not terminate even after signing what are called "Treaties of Settlement".

- Case of internal fighting among some constituents of Arab States.

- Weakness of some Arab regimes, and their subordinate to great states in contradictive alliances.

- Domination of some Arab regimes on their people after waves of Arab Revolutions since late days of the 2010 till the moment.

Studying the regional regimes covers structure and organization of the territories culturally, politically, economically and strategic interactions that happen at both levels internal and external and among territories, and so the relationship among these interactions and the international system, considered a vital factor in our understanding of the method by which behavior in the world is done, theorists of regional systems showed a group of explanations that reflect the internal regional relations, that is, among the units forming the regional system and external relations at both sides (Lubna, 2013).

It is worth indicating that the main goal of any regional system is to achieve stability in territory of the region, so stability of the system means amounting a stable level, that means conserving the acting condition, considered a basis to achieve stability, so the essence of stability due to the theory of systems is to achieve balance not in interests only, but in powers too. Achieving stability at any region has to start from agreement and regional cooperation, and not depending on bilateral relations (Al-Harbi, 2008).

And if we wanted measuring if the Arab region was peaceful, we could have taken the raised subject specified by (Benjamin Miller) in a study entitled (when and how the regions become peaceful?), for he pointed to three levels of the regional peace (Al-Harbi, 2008), they are:

Firstly: Cold peace is represented in absence of wars, and absence of threatening by using power among states of the region, and here the main issues of the regional conflict are in case of quietness inspite of that are not finally solved, but the relationships' basis is at the government level, and not at the level across national or non-governmental.

Secondly: Normal Peace that is most if not all the essential issues of the conflict had been solved, but this does not deny the possibility of breaking war, it is not too far from confrontation, and here relations begin among states to develop far from the government level.

Thirdly: Warm Peace meaning that using power is utterly a far thing as an alternative, but the nature of relations is that they are relations across large national, with a high degree of mutual regional dependence.

It is clear from what preceded that the Arab regional security is not available with the comprehensive meaning, for internal conflicts are multitude in their units, and in return there are conflicts and military interventions among units of the region, and the Arab systems have to know that the theoretical imagination and the practical one of the Arab regional security, cannot be achieved in shadow of these data, and so they should recount accounts inside the structure of the Arab systems, and nature of relations among units of the region including what guarantees achieving mutual security cooperation attaining an effective strategic theoretical formation. 


\section{Conclusion:}

It is divided into two parts they are: results and recommendations:

Firstly Results:

- The concept of Arab Regional Security is a synonym to the national security, and the total of national security for the states of the Arab Region, forms altogether the Arab Regional Security.

- Strategies of regional security are specified due to ability of the state on future planning to employ its human and materialistic abilities in stability and continuation of security attaining rise in all other domains.

- Comprehensive security is connected with the group security of states, because any defect in one necessarily negatively affects the security of other states.

- The Arab Regional Security depends on coordination among the security policies of Arab States, and cooperation in carrying them out.

- Reformation of the regional security theory of states due to civilized identity, and highest values of the Arab States altogether to confront internal and external dangers.

- Concern was devoted on the political security rather than else at a great degree

- Concern was concentrated on the military dimension of the national security, because of the Israeli occupation first, and the Arab Revolutions recently.

- Negligence of human security with all its dimensions: the economic, nutritive, environmental, social, political, and else.

Secondly: Recommendations:

- Necessity of working on enhancing the national security, in order to become supporting to the Arab Regional Security.

- Necessity of preparing strategies of the regional security at group form observing abilities of Arab states, and building security strategies with future planning to employ it in protecting stability of the regional security.

- Enhancing the security alliances to protect the comprehensive security, and connecting it with the group security of Arab States.

- Necessity of coordination among the security policies of Arab States, enhancing the Arab Regional Security, and motivating the machinery of cooperation in carrying them out.

- Necessity of working on reformation of the regional security theory of the states due to the civilized identity, and the highest values of the Arab States altogether to confront the internal and external dangers.

- Necessity of observing the other security dimensions and non-concentration on the political security alone.

- Necessity of concentration on the military dimension of security, and all other dimensions, affected at a great form, because of the Arab Spring Revolutions.

- Necessity of concern with the human security together with all its dimensions, because human security is originally from the security of native lands.

\section{References:}

\section{Arabic References:}

- Ismael, Mustafa Abdullah (2013). Future of Arab Group Security in Light of Arab Revolutions, Alexandria Bookshop, Egypt.

- Bobash, Mohammad (2010). Arab Regional Security in Light of Worldly Present Transformations, Journal of Middle Eastern Studies, Middle East Studies' Center, No. 53, P.32- 44.

- Jizan, Nizar Mu'ayyad (2011), Lectures on National Security, P. 9, available on site:www.ina.edu.sy/tbl-images/Filelectures16-7-2014-747pdf

- Haj, Miloud Amer (2016), Arab Regional Security and its Future Challenges, Dar Jamit Nayef for Publication, Riyadh, Saudi.

- Al-Harbi, Suleiman Abdullah (2008), Concept of Security: its levels, Formations and Threatenings (Theoretical Study in Concepts and the Frames), Arab Journal for Science and Politics, No. 6.

- Hussein, Zakareya (2000) National Security, Naser Military Academy, Cairo, Egypt Site of Islam Online, available across link:http:www.islamonline.net/Arabic/mafaheem

- $\quad$ Mahmoud Mohammad (2000), Security in Islam, Diane Loco, Egypt, Cairo.

- Rabe', Hamid Abdullah (1984), Theory of National Security (and Contemporary Development for the International Dealing in the Middle East Region), House of the Arab Stand for Journalism, Publication \& Distribution, Cairo, Egypt, PP. 72-352.

- Zaki, Abdel Mu'ti (2016), The National Security: A Reading in the Concept and Dimensions, The 
Egyptian Institute for Political and Strategic Studies, available one site: http://elpss-eg.org/wp-content/uploads

- Sa'del Deen, Ibrahim (2000), Getting Out of the Lane of History: Lessons of Great Ordeal in the Gulf, Dar Qiba', Cairo.

- Ahmad, Shuair (2016), Effect of International Terrorism on Al-Magharibi Security: A Case Study, Algeria, Master Degree Dissertation, Mawlay Al-Taher University, Political Science and International Relations Department,Algeria.

- Shalabi, Sa'd Shaker (2015), Arab Regional Security and the Competitive Regional Strategies Threats on Sovereignty in the Middle East Region, Dar Zahran for Publication \& Distribution, Amman, Jordan, PP. 88-120.

- Sheibi, Lekhmeisi (2009) International Security and the Relationship between (NATO) North Atlantic Treaty Organization and the Arab States- Period after the Cold War (1991-2008), Master Degree Dissertation, League of Arab States, Department of Political Studies, Cairo.

- $\quad$ Sayegh, Yazeed (1991), Arab Regional Security After Gulf War, Journal of Palestinian Studies, Vol. 2, No. 6.

- Al-Sulh, Raghidah Kathem (2015), For the Sake of Motivating the Arab Regional Integration, Journal of Arab Future, Vol. 36, NO. 418.

- Abdel Wahid, Izzat (2014) Theoretical Origination: Constituents and National Security Policies, Journal of International Politics, July, No. 197, PP. 33-38..

- $\quad$ Al-Azzazi, Sayed (2015), Key of Closed Gates to Understand Security and its Strategy, the Democratic Center, available on Site: https://democratic .de/?P=17041

- I'shqi, Anwar Bin Majid (2005), The Arab Security Strategy to confront Globalization, Center for the Strategic and Legal Studies, Riyadh, Saudi.

- Ghadeer, Aminah (2014), Effect of Environment Threats on Reality of Human Security in Africa, A Case Study: States of the African Peak, Master Degree Dissertation, University of Mohammed Khdeir, Political Science Department, Baskarah, Algeria.

- Al-Gharaibah, Faker Mohammad (2013), Challenges of Social Security in the Arab Community, Journal of Police Thinking, Vol. 21, No. 3.

- Lubna, Jassas (2013), Role of Regional Coalitions in Achieving the Regional Security, A Case Study: Bond of South East Asia, Master Degree Dissertation, University of Mohammad Khader, Political Science Department, Algeria .

- Mohyi, Abdel Hameed Mu'taz (2014), Terrorism and Renewal Security Thinking, Dar Zahran for Publication \& Distribution, Amman, Jordan.

- $\quad$ Al-Marhoon, Abdel Jaleel (2006), Security of the Gulf Among three Theories, Riyadh Newspaper, No. 13766 , Issued on $3 / 3 / 2006$.

- Marhoon, Abdel Jaleel (2010), The Arab National Security a Vision in Challenges and Alternatives, Journal of Middle East Affairs, The Strategic Studies Center, No. 136, P. 114-120.

- Al-Marhoon, Abdel Jaleel (2016), Arab Security - Its Recent Developments, available on site AlJazeera Net: www.aljazeera.net/knowledgegate/opinions

- Mustafa, Abdel-Tawab (2013), Problematic and New Challenges, Future of Arab cooperation after Revolutions, Journal of International Politics, No. 192.

- Ka'wash, Yousef (1989), Arab Regional Security, Society of Cooperative Press Workers, Amman, Jordan,

- Manser, Jamal (2009), Transformations in the Concept of Security: from Security of Means to the Security Objectives, site of Baji Mukhtar A'nnabah University, available on site: https://revues.univ-ouargla.dz/index.php/numero-01-2009-dafair

- Al-Muneer, Mahmoud (2015), Arab National Security....Reality and Horizons of Future, available on site:www.stgcenter.org/.../497

- Nafia', Hasan (2015), Arab National Security Between Mistakes of the past, Present Challenges and Horizons of the Future, Journal of Arab Future, Center for Arab Unity Studies, No. 438.

- Wahibah, Tabani (2014), Al-Mutawasiti Security in the Strategy of the Atlantic Treaty: A Case Study (Phenomenon of Terrorism), Master Degree Dissertation in Political Science, Mawlood Ma'mmari University, Algeria.

- Nakirah Ya, Najdat Sabri (2011), The Legal Frame Work of the National Security, Dar Dejlah, Amman, Jordan.

\section{English References:}

- Buzan, B. (1983). People, states, and fear: The national security problem in international relations. 
Wheatsheaf Books.

- $\quad$ Buzan, B. (1991), New Patterns of Global Security in the Twenty- First Century, International Affairs, Royal Institute of International Affairs, Vol. 67, No. 3, P. 431-432.

- Stone M. (2009), Security According to Buzan: A Comprehensive Security Analysis, Security Discussion Papers Series I, spring, Columbia University, School of International and Public Affairs New York, USA, P.2.

- Holmquist, E., \& Rydqvist, J. (2016). The Future of Regional Security in the Middle East-Four Scenarios. FOI Report, 1-45.

- $\quad$ Wolfers, A. (1952). " National security" as an ambiguous symbol. Political science quarterly, 67(4), 481-502. 